\title{
Dietary Fibre Supplementation of a 'Normal' Breakfast Administered to Diabetics
}

\author{
D. R. R. Williams, W. P. T. James, and I. E. Evans \\ Medical Research Council, Dunn Clinical Nutrition Centre, Addenbrookes Hospital Cambridge, and West Suffolk Hospital, \\ Bury St. Edmunds, Suffolk, England
}

\begin{abstract}
Summary. The supplementation of a breakfast by $10 \mathrm{~g}$ of guar, pectin, agar or locust bean gum in powder form in 13 maturity onset, non-insulin dependent diabetics failed to decrease significantly the postprandial rise in plasma glucose and insulin seen after a similar meal without the supplement. The values of one hour post-prandial increment in blood glucose seen with guar powder were, for control meal (mean \pm SEM) $5.8 \pm 0.4 \mathrm{mmol} / \mathrm{l}$, for test, $5.7 \pm 0.5$; with pectin powder, control $6.4 \pm 0.8 \mathrm{mmol} / 1$, test $5.0 \pm$ $1.2 \mathrm{mmol} / 1$; with agar powder, control $7.5 \pm 1.0$, test $7.0 \pm 0.5$; with locust bean gum powder, control 5.9 \pm 1.0 , test $5.0 \pm 0.7$. The equivalent values for one hour insulin $(\mu \mathrm{U} / \mathrm{ml}$, mean $\pm \mathrm{SEM})$ were, for guar powder, $51 \pm 21$ and $51 \pm 16$; for pectin powder 60 \pm 24 and $63 \pm 17$; for agar powder, $27 \pm 9$ and $36 \pm$ 11 and, for locust bean gum powder $53 \pm 26$ and 62 \pm 18 . The guar, pectin and locust gum tended to form lumps, and all the substances tested were unpalatable in powder form producing feelings of abdominal discomfort and abnormal fullness. Administering the same quantity of guar or pectin in a well hydrated form (but not premixed with the carbohydrate portion of the food) to the same people under identical conditions did not enhance its effectiveness. Supplementing diets with any of these sources of dietary fibre in either of these forms and in these amounts is unlikely to be beneficial in the management of non-insulin dependent diabetes.
\end{abstract}

Key words: Diabetes mellitus, dietary fibre.

Investigators assessing the usefulness of dietary fibre in the management of diabetes have used several approaches. Some have examined the effect on glu- cose and insulin responses of the addition of dietary fibre and fibre analogues to liquid test meals [1, 2], while others have considered the effect of incorporating dietary fibre into foods such as bread, crispbread or marmalade $[1,3,4,5,6,7]$. A third approach has been to modify the diet by increasing the intake of dietary fibre from readily available foods but this involves altering the intake of nutrients such as carbohydrate, protein and fat [8] or changing from largely cooked to raw foods [9] so that the role of dietary fibre as such in the metabolic changes produced cannot be deduced. A fourth approach is to supplement frequently consumed foods of low fibre content with fibre in powder form. Although, with this approach, the dietary fibre supplement is not premixed with the carbohydrate portion of the meal and is not hydrated before administration, it would seem the most practicable means of fibre supplementation in diabetes and worthy of exploration.

We therefore investigated in the first part of this study, the effect on post-prandial glucose and insulin concentrations of adding one of four fibre compounds in powder form to a test breakfast administered to maturity-onset diabetics. In the second part, two of these compounds were fed in a semi-solid, well hydrated form as part of a meal with the same protein, fat and carbohydrate content as that used in the first part of the experiment. Preliminary results have already been reported for the guar containing meals [10].

\section{Subjects and Methods}

Volunteers were chosen from diabetics attending the West Suffolk Hospital, Bury St. Edmunds. Patients presenting with diabetes after the age of 35 and managed for at least two years without insulin therapy were deemed suitable for study. Thirteen volunteers (ten male, three female) were investigated in the first part of 
(a)

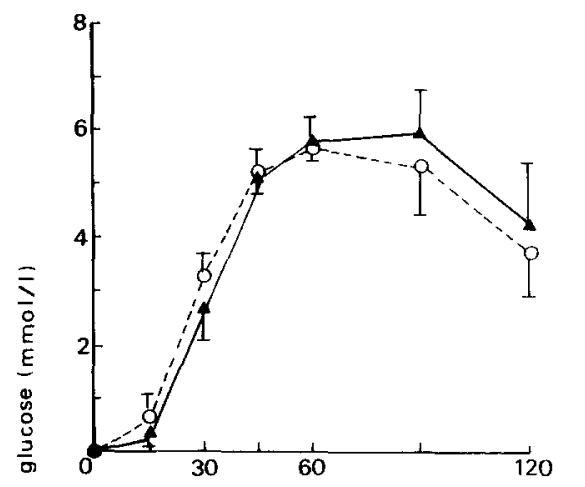

(c)

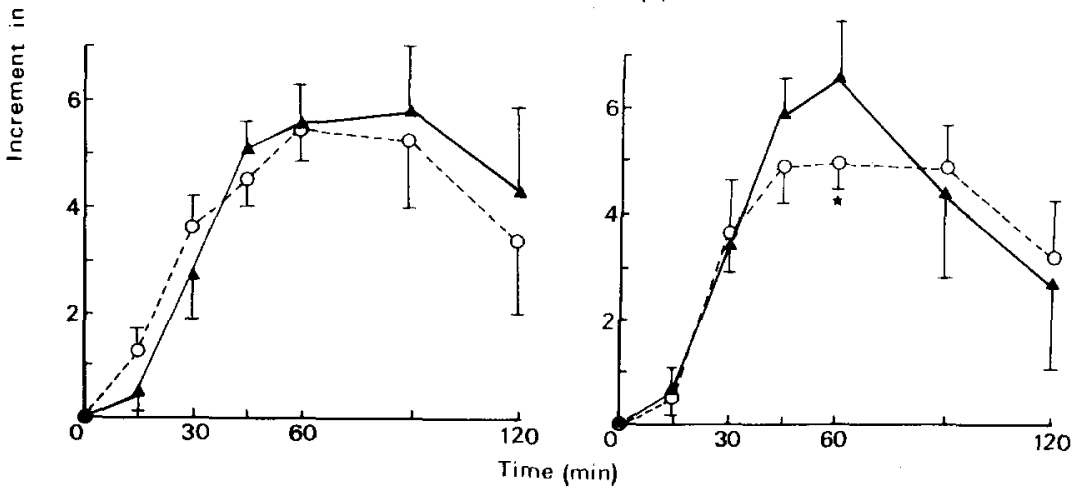

(b)

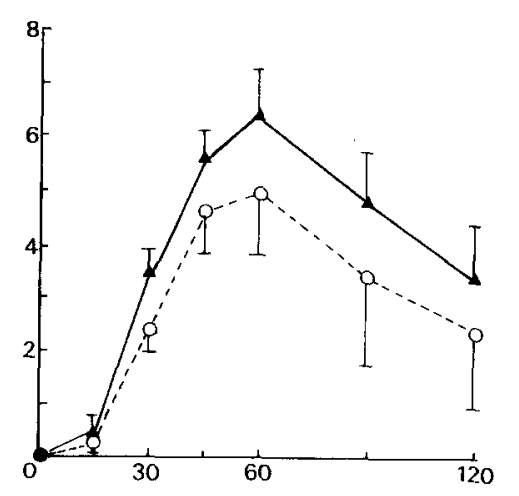

Fig. 1a-d. Increments in plasma glucose (mean \pm SEM) above fasting against time in minutes after starting the meal. $\Delta-\Delta$ control meals, $\mathrm{O}--\mathrm{O}$ meals with $10 \mathrm{~g}$ dietary fibre. a guar (in powder form), $\mathrm{n}=6 ; \mathbf{b}$ pectin (in powder form), $\mathrm{n}=7$; c guar (hydrated form), $\mathrm{n}=4 ; \mathbf{d}$ pectin (hydrated form), $n=4$. Statistically significant difference (t-test for paired samples) indicated by asterisk. Absolute fasting plasma glucose $(\mathrm{mmol} / 1$, mean $\pm \mathrm{SEM})$ for controls and tests: $\mathrm{a} 8.5 \pm 0.8$ and $8.6 \pm 0.8$, b $8.6 \pm 1.1$ and $9.1 \pm 1.3$, c $7.7 \pm 1.0$ and $7.8 \pm 0.8, \mathbf{d} 7.7 \pm 1.9$ and $6.3 \pm 0.6$. No statistically significant differences the experiment. Their ages at the time of study ranged from 39-64 years (mean $\pm \mathrm{SEM}, 55 \pm 2$ ). They weights ranged from $82 \%$ to $138 \%$ of the desirable weight for their height (mean \pm SEM, 110 \pm 4 ). Twelve of the patients were maintained on dietary therapy alone; one was taking $250 \mathrm{mg}$ of chlorpropamide daily. Three of the men had suffered previous myocardial infarctions and one was a chronic asthmatic (using a beclomethasone inhaler three times daily). No patients were receiving any other medication at the time of the study. Informed written consent was obtained from each subject before the first test meal was administered. Approval for the study had been given by the Ethical Committees of the Dunn Clinical Nutrition Unit and of the West Suffolk Hospital.

Each volunteer reported to the ward after a twelve hour fast. After 15 minutes resting in a chair, a fasting blood sample was taken before the meal was eaten over 15 minutes. Further blood samples were taken at $15,30,45,60,90$ and $120 \mathrm{~min}$, the subjects remaining seated throughout. Smoking was not allowed. The patient taking chlorpropamide omitted this on the mornings of the meals, and all subjects were urged to eat their customary diet for the week before the tests were carried out.

The test meal used in the first part of the experiment consisted of $30 \mathrm{~g}$ cornflakes with $200 \mathrm{ml}(204 \mathrm{~g})$ of milk and $15 \mathrm{~g}$ sucrose (eaten first), then $100 \mathrm{ml}$ of diabetic orange squash ( $20 \mathrm{ml}$ squash, $80 \mathrm{ml}$ water), followed by $35 \mathrm{~g}$ of white bread (with crusts removed) with $8 \mathrm{~g}$ of butter and $25 \mathrm{~g}$ of shredless marmalade, followed by $150 \mathrm{ml}$ of tea. The composition of the meal was protein $12 \mathrm{~g}$, fat $15.4 \mathrm{~g}$ and carbohydrate $84.9 \mathrm{~g}$.

Half of the fibre supplement in powder form was stirred vigorously into the orange squash, the remaining $5 \mathrm{~g}$ being sprinkled on the bread and butter before adding the marmalade. Each of the 13 subjects ate a control meal with no added fibre and eleven ate two further meals each supplemented by different fibre preparations
( $10 \mathrm{~g}$ of either guar ( 6 subjects), pectin ( 7 subjects), locust bean gum ( 5 subjects), or agar (4 subjects). The other two patients were tested with a single fibre preparation (one with locust bean gum, the other with agar). The meals were eaten in random order and each subject was tested with the fibre enriched meals within one week of receiving the control breakfast. Twenty four hours after each of the meals the subjects completed a questionnaire rating the meals in terms of palatability on a five point scale and reporting any nausea, vomiting, diarrhoea, excessive flatus or other symptoms.

In the second part of the experiment four of the subjects previously tested with guar and four tested with pectin in powder form received a modified test meal with either guar or pectin in a hydrated form as part of a mixture made up at least $24 \mathrm{~h}$ before administration and consisting of dietary fibre $(10 \mathrm{~g})$, cream $(20 \mathrm{~g})$, water $(130 \mathrm{ml})$, flavouring $(0.6 \mathrm{ml})$, colouring $(0.6 \mathrm{ml})$ and saccharin $(0.8 \mathrm{ml})$. The second meal was almost identical in terms of fat, protein and carbohydrate composition $(11.8 \mathrm{~g}, 15.4 \mathrm{~g}$ and $85.5 \mathrm{~g}$ respectively). Dried skimmed milk (17 g), made up with $170 \mathrm{ml}$ of water, was substituted for whole milk and $11 \mathrm{~g}$ of low fat spread ('Outline') for butter. The orange squash was eliminated altogether. Otherwise the quantities of foods were the same and the volume of fluid identical. The mixture containing the fibre preparation was eaten between the cereal course and the bread.

Plasma glucose levels were measured by the glucose oxidase method, and plasma insulin estimated by radioimmunoassay with a kit (The Radiochemicals Centre Ltd, Amersham, UK) using the double antibody technique (within assay coefficient of variation $₹$ $6.5 \%$ ).

Mean values of plasma glucose and insulin were compared using the $t$-test for paired values. Differences were deemed statistically significant at $p<0.05$. Areas under the curves were esti- 
(a)

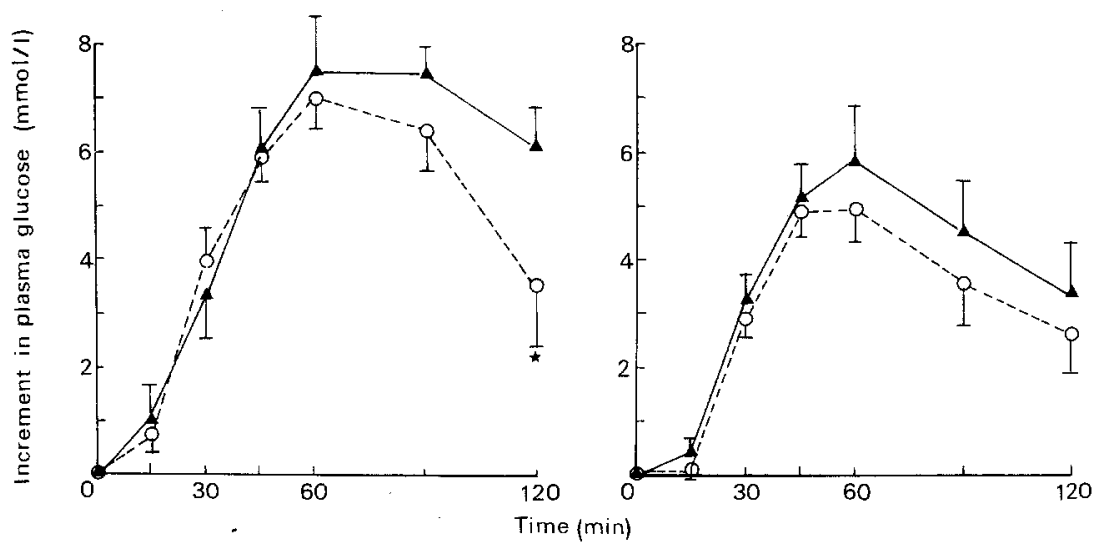

Fig. $2 \mathbf{a}$ and $\mathbf{b}$. Increments in plasma glucose above fasting (mean $\pm \mathrm{SEM}$ ) against time in minutes after starting the meal. $\boldsymbol{\Lambda}-\boldsymbol{\Lambda}$ control meals, O-_- $O$ meals with $10 \mathrm{~g}$ dietary fibre. a agar (in powder form), $\mathrm{n}=5 ; \mathrm{b}$ locust bean gum (in powder form), $\mathrm{n}=6$. Statistically significant difference ( $t$-test for paired samples) indicated by asterisk. Absolute fasting plasma glucose (mmol/l, mean $\pm \mathrm{SEM}$ ) for controls and tests: a $9.4 \pm 0.7$ and $9.4 \pm 0.5$, b $8.5 \pm 1.1$ and $8.8 \pm 1.3$. Neither difference statistically significant

Table 1. Effect of $10 \mathrm{~g}$ of dietary fibre supplement on post-prandial insulin

\begin{tabular}{|c|c|c|c|c|c|c|c|}
\hline \multirow[t]{2}{*}{ Meal } & \multirow[t]{2}{*}{$\mathrm{n}$} & \multicolumn{6}{|c|}{ Mean increment in plasma insulin $(\mu \mathrm{U} / \mathrm{ml} \pm \mathrm{SEM})$ at intervals after beginning meal } \\
\hline & & $15 \mathrm{~min}$ & $30 \mathrm{~min}$ & $45 \mathrm{~min}$ & $60 \mathrm{~min}$ & $90 \mathrm{~min}$ & $120 \mathrm{~min}$ \\
\hline $\begin{array}{l}\text { (a) Control } \\
+ \text { guar (powder) } \\
\text { (b) Control } \\
+ \text { guar (hydrated) }\end{array}$ & 6 & $\begin{array}{l}15( \pm 8) \\
13( \pm 8) \\
21( \pm 11) \\
25( \pm 5)\end{array}$ & $\begin{array}{l}35( \pm 14) \\
38( \pm 16) \\
39( \pm 21) \\
43( \pm 11)\end{array}$ & $\begin{array}{l}47( \pm 20) \\
54( \pm 14) \\
57( \pm 30) \\
37( \pm 10)\end{array}$ & $\begin{array}{l}51( \pm 21) \\
51( \pm 16) \\
58( \pm 33) \\
53( \pm 12)\end{array}$ & $\begin{array}{l}83( \pm 35) \\
47( \pm 5) \\
99( \pm 53) \\
64( \pm 17)\end{array}$ & $\begin{array}{l}46( \pm 8) \\
32( \pm 7) \\
36( \pm 9) \\
58( \pm 18)\end{array}$ \\
\hline $\begin{array}{l}\text { (c) Control } \\
+ \text { pectin (powder) } \\
\text { (d) Control } \\
+ \text { pectin (hydrated) }\end{array}$ & 7 & $\begin{array}{r}10( \pm 8) \\
8( \pm 2) \\
19( \pm 19) \\
23( \pm 7)\end{array}$ & $\begin{array}{l}28( \pm 13) \\
25( \pm 8) \\
43( \pm 21) \\
52( \pm 23)\end{array}$ & $\begin{array}{l}53( \pm 24) \\
45( \pm 12) \\
81( \pm 38) \\
75( \pm 34)\end{array}$ & $\begin{array}{l}60( \pm 24) \\
63( \pm 17) \\
88( \pm 37) \\
54( \pm 22)\end{array}$ & $\begin{array}{l}63( \pm 34) \\
48( \pm 12) \\
92( \pm 57) \\
52( \pm 13)\end{array}$ & $\begin{array}{l}30( \pm 8) \\
29( \pm 3) \\
29( \pm 10) \\
42( \pm 15)\end{array}$ \\
\hline $\begin{array}{l}\text { (e) Control } \\
+ \text { agar (powder) }\end{array}$ & 5 & $\begin{array}{l}4( \pm \quad 3) \\
8( \pm 5)\end{array}$ & $\begin{array}{l}18( \pm 9) \\
25( \pm 9)\end{array}$ & $\begin{array}{l}19( \pm 7) \\
28( \pm 9)\end{array}$ & $\begin{array}{l}27( \pm 9) \\
36( \pm 11)\end{array}$ & $\begin{array}{l}42( \pm 11) \\
43( \pm 8)\end{array}$ & $\begin{array}{l}30( \pm 10) \\
28( \pm 8)\end{array}$ \\
\hline $\begin{array}{l}\text { (f) Control } \\
+ \text { locust bean } \\
\text { gum (powder) }\end{array}$ & 6 & $\begin{array}{l}8( \pm 5) \\
6( \pm 2)\end{array}$ & $\begin{array}{l}30( \pm 9) \\
38( \pm 5)\end{array}$ & $\begin{array}{l}52( \pm 26) \\
58( \pm 18)\end{array}$ & $\begin{array}{l}53( \pm 26) \\
62( \pm 18)\end{array}$ & $\begin{array}{l}46( \pm 15) \\
44( \pm 8)\end{array}$ & $\begin{array}{l}32( \pm 8) \\
43( \pm 14)\end{array}$ \\
\hline
\end{tabular}

Absolute fasting values of plasma insulin (mean $\pm \mathrm{SEM}, \mu \mathrm{U} / \mathrm{ml}$ ), controls and tests respectively: (a) $14.7 \pm 2.1$ and $12.5 \pm 3.6$ (b) $15.0 \pm$ 3.3 and $15.8 \pm 1.4$, (c) $18.4 \pm 4.6$ and $15.3 \pm 2.6$, (d) $13.0 \pm 3.7$ and $16.0 \pm 3.6$, (e) $15.8 \pm 2.8$ and $19.2 \pm 2.2$, (f) $20.6 \pm 2.2$ and $16.2 \pm$ 3.0. No statistically significant differences

mated by the summation of areas of triangles and rectangles subtended by the lines joining the glucose and insulin values at each time point after the beginning of the meal.

\section{Results}

\section{Glucose and Insulin}

Figure 1 compares the mean rise in plasma glucose concentrations after the control meals and the breakfasts containing guar and pectin in powdered form (a and b) and in hydrated form ( $c$ and d). Figure 2 illustrates the effect of agar and locust bean gum in powdered form. Table 1 shows the response to each fibre supplement in terms of plasma insulin.

The decrease in plasma glucose response was small in all cases, being most marked during the second half of the test. The differences between control and test values achieved statistical significance 120 minutes after the agar-rich meal and 60 minutes after the meal supplemented with pectin in the hydrated form. Plasma insulin values were decreased only during the second half of the guar supplemented meals and these changes were not statistically significant. Hydration of the guar and pectin supplements produced no significantly greater fall in the glucose or insulin responses. When the areas under the curves were compared they did not reveal any statistically significant effects of the fibre supplements either in the first hour or during the entire test period.

\section{Palatability of the Meals and Side-effects}

All patientes noted that the addition of the powder to the meal reduced its palatability. None of the substances was considered to be completely unaccept- 
able, but the texture of the modified foods was found to be unpleasant. Guar and locust bean gum, and particularly pectin, coated the teeth and palate with a sticky film which was difficult to remove. These three fibre preparations also tended to form lumps when mixed with the orange squash. Several patients described a feeling of abnormal fullness which lasted throughout the morning with excessive flatus and mild abdominal discomfort later in the day.

The supplements were considered to be more acceptable in the hydrated form, although the pectin mixture was slightly acid in taste and produced some nausea in one subject. Two subjects complained of excessive flatus after the pectin meal and two after the guar. Diarrhoea was noted by one subject the evening after eating the pectin-supplemented meal.

\section{Discussion}

Monitoring the effect on blood glucose and insulin response after the addition of dietary fibre to liquid test meals $[1,2]$ is a convenient method of investigating the gastro-intestinal and metabolic effects of fibre. With this approach the stabilizing effect on blood glucose seems to be closely related to the calculated viscosity of the hydrated fibre compound [2]. This form of test meal, however, bears no resemblance to a normal meal or to the type of food traditionally considered suitable for a diabetic patient. Thus any substance of high viscosity and capable of converting a liquid into a solid meal will tend to reduce the post prandial response by slowing the rate of entry of carbohydrate into the duodenum.

The results from the first part of this experiment demonstrate that insignificant changes in post-prandial glucose and insulin result when powdered fibre is sprinkled onto food, even though similar quantities added to liquid test meals markedly depress the glucose and insulin response curves [2].

In powder form, guar, pectin and locust bean gum tended to form lumps when mixed in orange squash or eaten with bread, butter and marmalade. Agar was more readily miscible. In the second part of the experiment little effect was achieved even after the same quantities of guar and pectin had been thoroughly mixed into a blancmange of uniform consistency, without lumps. Studies with the same fibre compounds in similar doses have shown a significant depression in post-prandial responses when the fibre has been added to either the bread, soup, mashed potato or crispbread components of test meals $[4,6$, 7]. These differences suggest that to reduce effectively the response in post-prandial glucose and insulin the fibre supplement must be administered with the major carbohydrate content of the meal or that the timing of the fibre supplement in relation to the comsumption of the remainder of the meal is crucial. Heaton et al. [11] have suggested that it is important to maintain the natural physical relationship between starch and fibre but the effectiveness of enriching bread with guar suggests that the addition of fibre to cooked starch is also effective. This approach would, however, require the co-operation of food manufacturers in the production of a wide range of diabetic foods and would make difficult the manipulation of fibre dosage, if this proved necessary. The long-term results of other metabolic effects of feeding guar and pectin, for example on the absorption of minerals and fat soluble vitamins, would also have to be assessed.

We were impressed by the unpalatability as well as the ineffectiveness of the fibre supplement in the powdered form. Presenting the fibre in a hydrated state increased its palatability but not its effectiveness. Clearly this aspect is of paramount importance when a life long dietary regime is contemplated. Tredger and Ransley [12] have reported that certain food products are acceptable to diabetics even when they contained $5 \mathrm{~g}$ of guar per portion. When cheese biscuits were made with differing amounts of guar, most partients chose the biscuits with the least added fibre.

Given the ineffectiveness and unpalatability of powdered fibre supplements in diabetics and the manufacturing changes required for the production of fibre-enriched foods, the most practical way of improving the management of the diabetic may be to use naturally occurring high fibre foods. Unfortunately, simultaneous changes in fibre and carbohydrate intake have been made in previous investigations adopting this approach $[8,9]$ making it impossible to identify dietary fibre as the effective dietary component. The amount of dietary fibre needed for a therapeutic effect remains uncertain. It seems clear, however, that dietary fibre is likely to be most effective only when the fibre is closely associated with the main source of carbohydrate. Of equal importance for the management of the diabetic is the palatability of the modified diet.

Acknowledgements. We are grateful to the Hercules Powder Company Ltd., and to Steetley Chemicals Ltd., for supplying the dietary fibre and to Dr. J. H. Cummings of the Dunn Clinical Nutrition Centre for valuable advice. Dr. F. C. Harris and Dr. D. R. Stevens of the West Suffolk Hospital were responsible for blood glucose estimations. Mrs. Sheila Bingham of the Dunn Clinical Nutrition Centre and Mrs. J. Pidgeon of the West Suffolk Hospital assisted in the preparation and administration of the meals, and Mrs. D. Claydon, Mrs. A. S. Blake and Mrs. M. J. Rundle with secretarial work. We are very grateful to the diabetic patients who participated in this study. D. R. R. W. is in receipt of an M. R. C. Training Fellowship. 


\section{References}

1. Jenkins D J A, Leeds A R, Gassull M A, Cochet B, Alberti K GM M (1977) Decrease in post-prandial insulin and glucose concentrations by guar and pectin. Ann Intern Med 86: 20-23

2. Jenkins D J A, Wolever T M S, Leeds A R, Gassull M A, Haisman P, Delawari J, Goff D V, Metz GL, Alberti K GMM (1978) Dietary fibres, fibre analogues, and glucose tolerance: importance of viscosity. Br Med J I: 1392-1394

3. Jenkins D J A, Goff DV, Leeds A R, Alberti KGMM, Wolever T M S, Gassull M A, Hockaday T D R (1976) Unabsorbable carbohydrates and diabetes: decreased post-prandial hyperglycaemia. Lancet II: 172-174

4. Jenkins D J A, Wolever T M S, Hockaday T D R, Leeds A R, Howarth R, Bacon S, Apling E C, Delawari J (1977) Treatment of diabetes with guar gum. Lancet II: 779-780

5. Miranda PM, Horowitz D L (1978) High fibre diets in the treatment of diabetes mellitus. Ann Intern Med 88: 482-486

6. Jenkins D J A, Wolever T MS, Nineham R, Taylor R, Metz G L, Bacon S, Hockaday T D R (1978) Guar crispbread in the diabetic diet. Br Med J II: 1744-1746

7. Goulder T J, Alberti K G M M, Jenkins D A (1978) Effect of added fiber on the glucose and metabolic response to a mixed meal in normal and diabetic subjects. Diabetes Care 1: $351-355$

8. Kiehm, T G, Anderson J W, Ward K (1976) Beneficial effects of a high carbohydrate, high fibre diet on hyperglycaemic diabetic men. Am J Clin Nutr 29: 895-899

9. Douglass J M (1975) Raw diet and insulin requirements. Ann Intern Med 82: 62

10. Williams D R R, James W P T (1979) Fibre and diabetes. Lancet I: $271-272$

11. Heaton KW (1973) Food fibre as an obstacle to energy intake. Lancet II: $1418-1421$

12. Tredger J, Ransley J (1978) Guar gum - its acceptability to diabetic patients when incorporated into baked food products. J Hum Nutr 32: 427-432

Received: February 28, 1979, and in final revised form: December 14, 1979

Dr. D. R. R. Williams

Dunn Clinical Nutrition Centre

Addenbrookes Hospital

Trumpington Street

Cambridge CB2 1QE

England 